Correspondence: H. Haick, Dept of Chemical Engineering and Russell Berrie Nanotechnology Institute, Technion - Israel Institute of Technology, Haifa 3200003, Israel. E-mail: hhossam@tx.technion.ac.il

Received: Jan 292014 | Accepted after revision: Feb 142014

Conflict of interest: Disclosures can be found alongside the online version of this article at www.erj.ersjournals.com

Acknowledgments: The authors acknowledge Dr Falk Fish from Orgenics Ltd (Yavne, Israel). Orgenics Ltd have expressed interest in commercialising this technology and provided funding this study. The company played no role in the study design, analysis of the data, or drafting of the manuscript.

\title{
References
}

World Health Organization. Global Tuberculosis Control 2010. Geneva, World Health Organization, 2010.

2 American Thoracic Society/Centers for Disease Control and Prevention. Targeted tuberculin testing and treatment of latent tuberculosis infection. ATS/CDC Statement Committee on Latent Tuberculosis Infection membership list, June 2000. http://www.cdc.gov/MMWR/PREVIEW/MMWRHTML/rr4906a1.htm

3 Dheda K, van Zyl Smit R, Badri M, et al. T-cell interferon- $\gamma$ release assays for the rapid immunodiagnosis of tuberculosis: clinical utility in high-burden vs. low-burden settings. Curr Opin Pulm Med 2009; 15: 188-200.

$4 \quad$ Lawn SD, Zumla AI. Tuberculosis. Lancet 2011; 378: 57-72.

5 Whiley DM, Tapsall JW, Sloots TP. Nucleic acid amplification testing for Neisseria gonorrhoeae: an ongoing challenge. J Mol Diagn 2006; 8: 3-15.

6 Theron G, Peter J, Meldau R, et al. Accuracy and impact of Xpert MTB/RIF for the diagnosis of smear-negative or sputum-scarce tuberculosis using bronchoalveolar lavage fluid. Thorax 2013; 68: 1043-1051.

7 Wallis RS, Pai M, Menzies D, et al. Biomarkers and diagnostics for tuberculosis: progress, needs, and translation into practice. Lancet 2010; 375: 1920-1937.

8 Broza YY, Kremer R, Tisch U, et al. A nanomaterial-based breath test for short-term follow-up after lung tumor resection. Nanomedicine 2013; 9: 15-21.

9 Wheelock CE, Goss VM, Balgoma D, et al. Application of 'omics technologies to biomarker discovery in inflammatory lung diseases. Eur Respir J 2013; 42: 802-825.

10 Phillips M, Cataneo RN, Condos R, et al. Volatile biomarkers of pulmonary tuberculosis in the breath. Tuberculosis 2007; 87: 44-52.

11 Peled N, Hakim M, Bunn PA Jr, et al. Non-invasive breath analysis of pulmonary nodules. J Thorac Oncol 2012; 7: $1528-1533$.

12 Dovgolevsky E, Tisch U, Haick H. Chemically sensitive resistors based on monolayer-capped cubic nanoparticles: towards configurable nanoporous sensors. Small 2009; 5: 1158-1161.

13 Peng G, Tisch U, Adams O, et al. Diagnosing lung cancer in exhaled breath using gold nanoparticles. Nat Nanotechnol 2009; 4: 669-673.

14 Elliott A, Namaambo K, Allen B, et al. Negative sputum smear results in HIV-positive patients with pulmonary tuberculosis in Lusaka, Zambia. Tubercle and Lung Disease 1993; 73: 191-194.

15 Greulich T, Hattesohl A, Grabisch A, et al. Detection of obstructive sleep apnoea by an electronic nose. Eur Respir J 2013; 42: 145-155.

\section{Rituximab in the treatment of refractory pulmonary sarcoidosis}

\author{
To the Editor:
}

Sarcoidosis is a chronic disease characterised by granulomatous depositions that can occur in virtually any organ system [1]. Currently, there is no US Food and Drug Administration (FDA)-approved therapy for sarcoidosis; however, corticosteroids have proven efficacious and are a commonly used treatment [2]. In patients with chronic or pulmonary disease who do not respond to corticosteroids, or in whom steroid use is contraindicated, agents such as methotrexate, azathioprine and tumour necrosis factor (TNF)- $\alpha$ antagonists may be effective $[3,4]$. However, a need persists for patients who fail to respond to current options.

Sarcoidosis is a T-cell-mediated disease; however, humoral mechanisms may play a role in its pathogenesis [5]. Sarcoidosis is often associated with hypergammaglobulinaemia, autoantibody production and circulating immune complexes [6].

B-cell-targeted therapies have shown positive results in many T-cell-mediated autoimmune diseases. Rituximab is a chimeric monoclonal antibody that causes depletion of CD20 ${ }^{+} \mathrm{B}$-cells [7]. Rituximab is FDA approved for the treatment of rheumatoid arthritis, granulomatosis with polyangiitis (Wegener's) and microscopic polyangiitis, and is also being studied in Sjögren's syndrome, systemic lupus erythematosus 
and vasculitis [8]. There have been case reports of the effectiveness of rituximab for sarcoidosis [9-11]. Given the evidence for humoral involvement in sarcoidosis pathogenesis, this study sought to evaluate the utility of B-cell depletion using rituximab in patients with refractory pulmonary sarcoidosis.

This was a prospective, open-label, phase I/II trial. The study was approved by the institutional review boards of the University of Chicago (Chicago, IL, USA) and the University of Cincinnati (Cincinnati, OH, USA), and all patients provided written, informed consent to participate (www.clinicaltrials.gov identifier NCT00855205).

Enrolled patients had histologically confirmed pulmonary sarcoidosis for $\geqslant 2$ years and were symptomatic despite use of corticosteroids (prednisone, $\geqslant 10 \mathrm{mg}$ a day) or any dose of prednisone plus one or more corticosteroid-sparing agents, including methotrexate and azathioprine. Patients had to have moderate-tosevere pulmonary disease with a forced vital capacity (FVC) between $30 \%$ and $80 \%$ of predicted, parenchymal involvement on chest radiography, and could have extrapulmonary disease. Chest radiographic abnormalities were classified by the staging method of SCADDING [12]. All patients were on a stable dose of medication for $\geqslant 3$ months prior to entry into the study. Exclusion criteria were current therapy with anti-TNF antibodies, severe left- or right-sided heart failure (New York Heart Association class III or IV), hepatitis B or C infection, history of tuberculosis disease, and live virus vaccination within the past 4 weeks, treatment with intravenous antibiotics within 2 months of screening or oral antibiotics within 2 weeks prior to screening.

Prior to the first dose, patients performed spirometry to measure FVC and FVC \% predicted. 6-min walk distance (6MWD) was determined using a previously described protocol. $1 \mathrm{~g}$ rituximab was administered i.v. at baseline and again 2 weeks later, and with pre-treatment and monitoring as previously described [5]. Patients were evaluated every 6 weeks for 1 year. In an effort to identify markers of response to rituximab therapy, markers of peripheral B-cell depletion were evaluated by measuring peripheral blood quantitative immunoglobulin levels including serum IgG, IgA and IgM, and $\mathrm{CD} 19^{+}$and $\mathrm{CD}_{4} 5^{+}$levels, initially and at weeks 24 and 52 .

The study's primary end-point was safety. Secondary end-points were change in FVC and 6MWD at weeks 24 and 52. Patients were considered responders if they achieved a $>5 \%$ absolute improvement in FVC and/or had a $>30-\mathrm{m}$ increase in 6MWD. Comparisons were made before and after therapy using the Wilcoxon test for paired samples. A p-value of $<0.05$ was considered significant. The sponsor had no role in the concept and design of study, methods, patient recruitment, data collection and analysis, or manuscript preparation.

Of the 15 patients screened for the study, five were ineligible for the study based on severity of their disease or prior infection with either tuberculosis (one patient) or hepatitis C. 10 patients (seven males; with median age 49 years, range $46-74$ years) were included in the study. Six patients were Caucasian, three African American and one of Indian descent. All patients were evaluated at week 24 but only eight patients presented for evaluation at week 52, the end of the study.

All patients had parenchymal lung disease demonstrated on chest radiography, with only one having significant mediastinal/hilar adenopathy (stage 2) while others were all stage 3.

One patient was hospitalised for pneumonia 2 weeks after the second treatment, which resolved with antibiotic treatment. No other serious adverse events have been observed. Two patients died because of respiratory failure during the study period. One patient died 30 weeks after the first rituximab treatment. The second was hospitalised for worsening of her sarcoidosis twice at weeks 30 and 48, and subsequently died 56 weeks after the first rituximab treatment. No evidence of infection was found in either of these patients after extensive investigation. It was presumed that they died from progression of sarcoidosis.

Initial FVC measurement, and changes in percentage of predicted FVC and 6MWD at weeks 24 and 52 for all patients are shown in table 1 . There was no significant difference in the FVC \% predicted at either 24 or 52 weeks compared with baseline. However, at 24 weeks, five patients had a $>5 \%$ absolute improvement in FVC $\%$ predicted and four patients had a $>10 \%$ improvement of FVC \% predicted. Two patients had a $>10 \%$ absolute improvement of FVC \% predicted at week 52 .

6MWD improved from initial value by $>30 \mathrm{~m}$ in five patients and by $>50 \mathrm{~m}$ in three patients at week 24 . Three patients had $>50 \mathrm{~m}$ improvement in 6MWD at week 52. Patient 1 had a $>50 \mathrm{~m}$ walk distance improvement at weeks 24 and 52 but had a small decline in his FVC \% predicted at these time-points. Patient 7 had a $45-\mathrm{m}$ improvement in his $6 \mathrm{MWD}$ at week 24 but had an absolute fall in FVC $\%$ predicted by $5.1 \%$. Chest radiographic stage remained unchanged throughout the study. The prednisone doses were not changed during the study. 
TABLE 1 Initial forced vital capacity (FVC) measurement, and changes in \% predicted FVC and 6-min walk distance (6MWD) at weeks 24 and 52

\begin{tabular}{|c|c|c|c|c|c|c|}
\hline Patient & $\begin{array}{l}\text { Initial FVC L } \\
\text { (\% predicted) }\end{array}$ & $\begin{array}{c}\text { Change in FVC \% } \\
\text { predicted at week } 24\end{array}$ & $\begin{array}{c}\text { Change in FVC } \% \\
\text { predicted at week } 52\end{array}$ & Initial 6MWD m & $\begin{array}{c}\text { Change in 6MWD at } \\
\text { week } 24 \mathrm{~m}\end{array}$ & $\begin{array}{c}\text { Change in } 6 \mathrm{MWD} \text { at } \\
\text { week } 52 \mathrm{~m}\end{array}$ \\
\hline 1 & $3.2(70)$ & -4.30 & 3.7 & 457 & 99 & 137 \\
\hline 3 & $1.6(52)$ & -6.7 & -9.1 & 389 & -15 & 23 \\
\hline 4 & $2.2(58)$ & -15.1 & -17.9 & 488 & -46 & -23 \\
\hline 5 & $2.4(74)$ & 15.2 & -7.0 & 610 & -84 & -84 \\
\hline 8 & $1.2(35)$ & -2.6 & ND & 213 & -213 & ND \\
\hline 9 & 2.7 (55) & 14.3 & 34.2 & 671 & 122 & 167 \\
\hline 10 & $1.3(38)$ & 8.5 & ND & 168 & 91 & ND \\
\hline
\end{tabular}

ND: not determined.

Serum IgG, IgA and IgM levels all fell significantly by week $24(\operatorname{IgG} \mathrm{p}<0.05 ; \operatorname{IgA} \mathrm{p}<0.05 ; \operatorname{IgM} \mathrm{p}<0.005)$. The percentage of $\mathrm{CD} 19^{+}$cells that were $\mathrm{CD} 45^{+}$also fell significantly $(\mathrm{p}<0.002)$ and no patient had $>3 \%$ $\mathrm{CD} 19^{+} / \mathrm{CD} 45^{+}$cells at week 24 . Comparison of efficacy findings for the seven responders and three nonresponders showed no difference in the initial IgG, IgA, IgM or CD $19^{+} / \mathrm{CD} 45^{+}$cell levels.

The current study was the first prospective phase I/II clinical trial to evaluate the use of rituximab in patients with refractory pulmonary sarcoidosis. We observed the clinical response to rituximab therapy to be inconsistent among patients with refractory pulmonary sarcoidosis. Respiratory function improved in only a subset of our study cohort: five patients had $>5 \%$ absolute improvement in FVC and five patients improved by $>30 \mathrm{~m}$ in 6MWD (seven responders total; some patients improved in only FVC or 6MWD, others improved in both). We were not able to correlate response to rituximab with pre-treatment immunoglobulin levels. Further studies are required to assess whether rituximab may be a viable alternative to anti-TNF antibodies for refractory sarcoidosis. In addition, it should be defined which subgroup of patients is likely to respond to rituximab therapy.

@ERSpublications

Rituximab may be considered as third-line therapy for refractory pulmonary sarcoidosis http://ow.ly/sLmtD

Nadera J. Sweiss ${ }^{1}$, Elyse E. Lower ${ }^{2}$, Mehdi Mirsaeidi ${ }^{3}$, Steven Dudek ${ }^{3}$, Joe G.N. Garcia ${ }^{4}$, David Perkins ${ }^{5}$, Patricia W. Finn ${ }^{3}$ and Robert P. Baughman ${ }^{6}$

${ }^{1}$ University of Illinois Hospital and Health Sciences System, Chicago, IL, ${ }^{2}$ University of Cincinnati Medical Center, Cincinnati, OH, ${ }^{3}$ Division of Pulmonary and Critical Care, University of Illinois, Chicago, IL, ${ }^{4}$ University of Arizona, Tucson, AZ, ${ }^{5}$ Dept of Surgery, University of Illinois, Chicago, IL, and ${ }^{6}$ University of Cincinnati Medical Center, Interstitial Lung Disease and Sarcoidosis Clinic Dept of Internal Medicine, Cincinnati, OH, USA.

Correspondence: N.J. Sweiss, University of Illinois Hospital and Health Sciences System, 840 S. Wood Street, MC 733, Chicago, IL 60612, USA. Email: nsweiss@uic.edu

Received: Nov 052013 | Accepted after revision: Jan 102014 | First published online: Jan 312014

Support statement: N.J. Sweiss, E.E. Lower and R.P. Baughman received grants from Genentech for this project.

Conflict of interest: Disclosures can be found alongside the online version of this article at www.erj.ersjournals.com

Clinical trial: This study is registered at www.clinicaltrials.gov with identifier number NCT00855205.

\section{References}

1 Baughman RP, Culver DA, Judson MA. A concise review of pulmonary sarcoidosis. Am J Respir Crit Care Med 2011; 183: 573-581.

2 Baughman RP, Nunes H. Therapy for sarcoidosis: evidence-based recommendations. Expert Rev Clin Immunol 2012; 8: 95-103.

3 Sweiss NJ, Curran J, Baughman RP. Sarcoidosis, role of tumor necrosis factor inhibitors and other biologic agents, past, present, and future concepts. Clin Dermatol 2007; 25: 341-346.

4 Korsten P, Mirsaeidi M, Sweiss NJ. Nonsteroidal therapy of sarcoidosis. Curr Opin Pulm Med 2013; 19: 516-523.

5 Lee NS, Barber L, Akula SM, et al. Disturbed homeostasis and multiple signaling defects in the peripheral blood Bcell compartment of patients with severe chronic sarcoidosis. Clin Vaccine Immunol 2011; 18: 1306-1316. 
Dall'Aglio PP, Pesci A, Bertorelli G, et al. Study of immune complexes in bronchoalveolar lavage fluids. Respiration 1988; 54: Suppl. 1, 36-41.

7 Reff ME, Carner K, Chambers KS, et al. Depletion of B cells in vivo by a chimeric mouse human monoclonal antibody to CD20. Blood 1994; 83: 435-445.

8 Puechal X, Gottenberg JE, Berthelot JM, et al. Rituximab therapy for systemic vasculitis associated with rheumatoid arthritis: results from the AutoImmunity and Rituximab Registry. Arthritis Care Res (Hoboken) 2012; 64: 331-339.

9 Bomprezzi R, Pati S, Chansakul C, et al. A case of neurosarcoidosis successfully treated with rituximab. Neurology 2010; 75: 568-570.

10 Lower EE, Baughman RP, Kaufman AH. Rituximab for refractory granulomatous eye disease. Clin Ophthalmol 2012; 6: 1613-1618.

11 Belkhou A, Younsi R, El Bouchti I, et al. Rituximab as a treatment alternative in sarcoidosis. Joint Bone Spine 2008; 75: 511-512.

12 Scadding JG. Prognosis of intrathoracic sarcoidosis in England. A review of 136 cases after five years' observation. Br Med J 1961; 2: 1165-1172.

Eur Respir J 2014; 43: 1525-1528 | DOI: 10.1183/09031936.00224513 | Copyright @eERS 2014 